\title{
ON FINDING DEPRESSED PATIENTS FOR CLINICAL TRIALS
}

\author{
N. BOURAS, H. STANDISH-BARRY, P.K. BRIDGES \& M. AL-YASSIRI \\ Academic Unit for Clinical Psychopharmacology, Guy's Hospital Medical School, \\ London SE1 9RT
}

\begin{abstract}
A special clinic was set up in an attempt to overcome the problem of accumulating a sufficient number of depressed patients for inclusion in clinical trials. Only 21 patients of the 81 patients referred during 1 year fulfilled the criteria for inclusion in the trials. The function of the special clinic did not prove successful as a similar proportion of depressed patients was found in a comparison group referred to the district psychiatric outpatient clinic.
\end{abstract}

\section{Introduction}

In recent years there have been reports pointing out the difficulty of finding suitable patients for inclusion in trials of new antidepressant agents (Little et al., 1978). This adds further to the already considerable methodological difficulties in establishing their clinical effectiveness (Jenner, 1977; Blackwell \& Shepherd, 1967).

In an attempt to overcome this problem, a special Rapid Assessment Clinic was set up where patients were seen within $24 \mathrm{~h}$ of referral. It was felt that an easily available specialised assessment would encourage general practitioners to refer more of their depressed patients before commencing medication.

Those patients who attended the Rapid Assessment Clinic during its first year of operation were compared with a group of consecutive new referrals to a general psychiatric outpatient clinic held near to the site of the Special Clinic. Our aims were to establish, firstly, whether there were any differences between the two groups and, secondly, whether the Rapid Assessment Clinic proved a more fruitful source of depressed patients suitable for inclusion in a clinical trial.

\section{Methods}

At the time of the study, the Academic Unit for Clinical Psychopharmacology at Guy's Hospital was conducting clinical trials on two new antidepressant agents. The inclusion criteria used to judge suitability for admission to the trials were as reported by the Medical Research Council (1965).

All family doctors in the Guy's Health District were informed by letter of the Rapid Assessment Clinic and invited to refer any patient needing urgent assessment of a lowered mood state. Patients were seen within $24 \mathrm{~h}$ of a telephone request, from Monday to Friday. A full mental state assessment was carried out, and, if suitable and consenting, the patient was included in the clinical trial. If the patient was judged unsuitable he or she was referred to the appropriate local psychiatric service.

Demographic and clinical characteristics were recorded on a specially devised form and all patients completed the Wakefield self assessment depression inventory (Snaith et al., 1971).

\section{Results}

A total of 81 patients ( 26 men and 55 women) with a mean age of 36.8 years (s.d. \pm 12.9 ) were referred to the Rapid Assessment Clinic during the first year. These patients were compared with 80 consecutive new referrals ( 30 men and 50 women; mean age 39.5 years s.d. \pm 12.3 ) to the regular district outpatient clinic during one year. None of the unsuitable patients of those referred to the Rapid Assessment Clinic was included in the comparison group. There were no statistically significant differences in the sex ratios nor in the mean ages of the two groups.

Only $28 \%$ of the rapid assessment group were not taking any medication at the time they were seen, while $14 \%$ were already on antidepressants. Findings in the routine outpatient clinic were similar with $30 \%$ not taking any medication and $15 \%$ already on antidepressants.

The diagnosis of depression was made according to 
Medical Research Council (1965) criteria. The numbers of patients in the main diagnostic categories for each group appear in Table 1 .

The mean score for the Wakefield scale for the Rapid Assessment Clinic group was 28.1 (s.d. \pm 17.2 ) and for the outpatients' sample 21.3 (s.d. \pm 10.1 ). Patients referred to the assessment clinic had significantly higher scores than those at the outpatient clinic $(t=3.4, P<0.001)$.

Table 1 Diagnosis

\begin{tabular}{lrrrr}
\hline & \multicolumn{2}{c}{ Rapid assessment clinic } & \multicolumn{2}{c}{ Outpatients } \\
& $\mathrm{n}$ & $\%$ & $\mathrm{n}$ & $\%$ \\
& & & & \\
Depression & 28 & 34.6 & 30 & 37.0 \\
Anxiety neurosis & 13 & 16.0 & 18 & 22.5 \\
Schizophrenia & 5 & 5.1 & 8 & 10.9 \\
Personality disorders & 24 & 30.6 & 22 & 27.2 \\
Others & 11 & 13.7 & 2 & 2.4 \\
\multicolumn{1}{c}{$\quad$ Total } & 81 & 100.0 & 80 & 100.0
\end{tabular}

Table 2 , however, shows that only 21 patients $(26 \%)$ from the assessment clinic group fulfilled all the MRC criteria for inclusion in the clinical trials. Similarly only 18 patients $(23 \%)$ from the outpatient group fulfilled all inclusion criteria for entry to the trials.

Table 2 Percentage of unsuitable and suitable patients

\begin{tabular}{ccc}
\hline & $\begin{array}{c}\text { Rapid assessment } \\
\text { clinic } \\
(\mathrm{n}=81)\end{array}$ & $\begin{array}{c}\text { Outpatien } \\
\text { clinic } \\
(\mathrm{n}=80) \\
\%\end{array}$ \\
Unsuitable for trials: & & \\
On antidepressants & 14 & 15 \\
On other medication & 58 & 55 \\
Failed entry criteria & 2 & 7 \\
Total & 74 & 77 \\
Suitable for trials: & 26 & 23 \\
Total & 100 & 100
\end{tabular}

\section{References}

BLACKWELL, B. \& SHEPHERD, M. (1967). Early evaluation of psychotropic drugs in man: A trial that failed. Lancet, ii, 819.

JENNER, F.A. (1977). Some of the problems and difficulties associated with clinical studies of antidepressant agents. Br. J. clin. Pharmac., 4, 195S-207S.

LITTLE, J.C., KERR, T.A. \& MCCLELLAND, H.A. (1978). Where are the untreated depressives? Br. med. J., 2, 1593-1594.

\section{Discussion}

This study shows the difficulty in finding patients suffering from depression who are not on medication for inclusion in clinical trials of new antidepressant agents. The validity of the results of these trials will be seriously questioned if they are not based on adequate numbers of such depressed patients and the further advance of psychopharmacology in establishing new effective and safer treatments with fewer side-effects will be greatly hampered.

In our study the setting up of a special Rapid Assessment Clinic gave no advantage in finding suitable cases of depression over a routine outpatient clinic. It is noteworthy, although to be expected, that, on average, the patients attending the Rapid Assessment Clinic showed significantly more severely depressed mood as measured by the Wakefield Scale.

Although in both groups there was a considerable proportion of depressed patients, 34 and $37 \%$ respectively ( $14 \%$ from the assessment clinic group and $15 \%$ from the outpatients), many of those could not be included in the trials because they were already on antidepressant medication prescribed by their family doctors.

It is concluded that depressed patients suitable for inclusion in drug trials are still seen but the great majority ( 72 and $70 \%$ ) are already on medication, not necessarily antidepressant. This finding suggests that general practitioners tend to prescribe for depressed patients at an early stage and may refer them to psychiatrists at a later stage. It might be useful for future psychopharmacology research to be conducted by psychiatrists attached to general practices (Little $e t$ al., 1978). It would then be more practical and easier for depressed patients to be selected for clinical trials as soon as their illness is diagnosed.
MEDICAL RESEARCH COUNCIL. (1965). Clinical trial of the treatment of depressive illness. Br. med. J., 1, $881-886$.

SNAITH, R.P., AHMED, S.N., MEHTA, S. \& HAMILTON, M. (1971). The assessment of the severity of primary depressive illness. Psychol. Med., 1, 143-149.

(Received July 26, 1982, accepted December 14, 1982) 